\title{
Performance Enhancement of a Full-Scale Vertical Tail Model Equipped with Active Flow Control
}

\author{
Edward A. Whalen* \\ The Boeing Company, Hazelwood, MO, 63042, USA \\ Douglas Lacy ${ }^{\dagger}$ \\ The Boeing Company, Seattle, WA, 98124, USA \\ John C. Lin*, Marlyn Y. Andino ${ }^{\S}$, Anthony E. Washburn ${ }^{* *}$ \\ NASA Langley Research Center, Hampton, VA, 23681, USA \\ Emilio Graff ${ }^{\dagger \dagger}$ \\ California Institute of Technology, Pasadena, CA 91125, USA \\ Israel J. Wygnanski ${ }^{\text {t木 }}$ \\ The University of Arizona, Tucson, AZ, 85721, USA
}

\begin{abstract}
This paper describes wind tunnel test results from a joint NASA/Boeing research effort to advance active flow control (AFC) technology to enhance aerodynamic efficiency. A fullscale Boeing 757 vertical tail model equipped with sweeping jet actuators was tested at the National Full-Scale Aerodynamics Complex (NFAC) 40- by 80-Foot Wind Tunnel (40x80) at NASA Ames Research Center. The model was tested at a nominal airspeed of 100 knots and across rudder deflections and sideslip angles that covered the vertical tail flight envelope. A successful demonstration of AFC-enhanced vertical tail technology was achieved. A 31actuator configuration significantly increased side force (by greater than $20 \%$ ) at a maximum rudder deflection of $30^{\circ}$. The successful demonstration of this application has cleared the way for a flight demonstration on the Boeing 757 ecoDemonstrator in 2015.
\end{abstract}

Nomenclature

$\begin{aligned} \mathrm{AFC} & =\text { active flow control } \\ \mathrm{CFD} & =\text { computational fluid dynamics } \\ \mathrm{C}_{\mathrm{y}} & =\text { side force coefficient } \\ \mathrm{C}_{\mu} & =\text { momentum coefficient, } \% \\ \mathrm{C}_{\pi} & =\text { power coefficient, } \% \\ \mathrm{ERA} & =\text { Environmentally Responsible Aviation } \\ \mathrm{LE} & =\text { leading edge } \\ \mathrm{M}_{\infty} & =\text { free stream Mach number } \\ \mathrm{m}_{\mathrm{dot}} \text { or } \dot{m}= & \text { total mass flow rate, } 1 \mathrm{bm} / \mathrm{sec} \\ \mathrm{NFAC} & =\text { National Full-Scale Aerodynamics } \\ & \text { Complex }\end{aligned}$
$\mathrm{P}_{\text {Act_Inlet }}=$ averaged actuator inlet pressure, psi
$\operatorname{Re} \quad=$ Reynolds number based on mean aerodynamic chord
$\mathrm{U}_{\infty} \quad=$ free stream velocity, knots
$\mathrm{VG}=$ vortex generators
$\beta=$ sideslip angle, degrees
$\delta_{\text {Rudder }}=$ flap deflection angle, degrees
$\% \Delta \mathrm{C}_{\mathrm{y}}=\%$ difference in $\mathrm{C}_{\mathrm{y}}$ with respect to $\mathrm{AFC}$ off, $100 \% *\left(\mathrm{C}_{\mathrm{y}}-\mathrm{C}_{\mathrm{y}, \mathrm{AFC} \text { off }}\right) / \mathrm{C}_{\mathrm{y}, \mathrm{AFC} \text { off }}$

\footnotetext{
${ }^{*}$ R \& D Engineer, Boeing Research \& Technology, Mail Stop: S306-4030, AIAA Senior Member

${ }^{\dagger}$ Product Development Engineer, Boeing Commercial Airplanes, PO Box 3707, M/S 0R-MM, AIAA Senior Member

* Aerospace Engineer, Flow Physics and Control Branch, MS 170, AIAA Associate Fellow

$\S$ Aerospace Engineer, Flow Physics and Control Branch, MS 170, AIAA Senior Member

** AeroScience Lead, Flow Physics and Control Branch, MS 41

${ }^{\dagger \dagger}$ Research Project Manager, Graduate Aerospace Laboratories, AIAA Member

\# Professor, Aerospace and Mechanical Engineering Department, AIAA Fellow
} 


\section{Introduction}

$\mathrm{T}$ he vertical tail on modern, multi-engine commercial transport aircraft is typically sized to overcome the emergency situation of an engine failure at low airspeed (see Figure 1). As a result, it is oversized under normal operating conditions, but it is indispensible during an "engine out" emergency at low speeds. In addition, the vertical tail is usually sized for the shortest version in an aircraft model family, but used for every version in the family. This effectively makes the common vertical tail oversized for the longer versions (longer moment arm) in the family. Sized in this way, the vertical tail adds drag and weight that increases the fuel consumption of the entire aircraft family. Active flow control (AFC) devices can be employed to delay flow separation over a highly deflected rudder and increase the side force that it generates. This may enable a smaller vertical tail that provides the control authority needed during an emergency situation using AFC, while operating in a conventional manner over the rest of the flight envelope. A system integration study indicated that such a vertical design could result in weight and drag reduction as well as increased fuel efficiency. These benefits are of significant interest to the NASA Environmentally Responsible Aviation (ERA) project $[1,2]$ and Boeing.

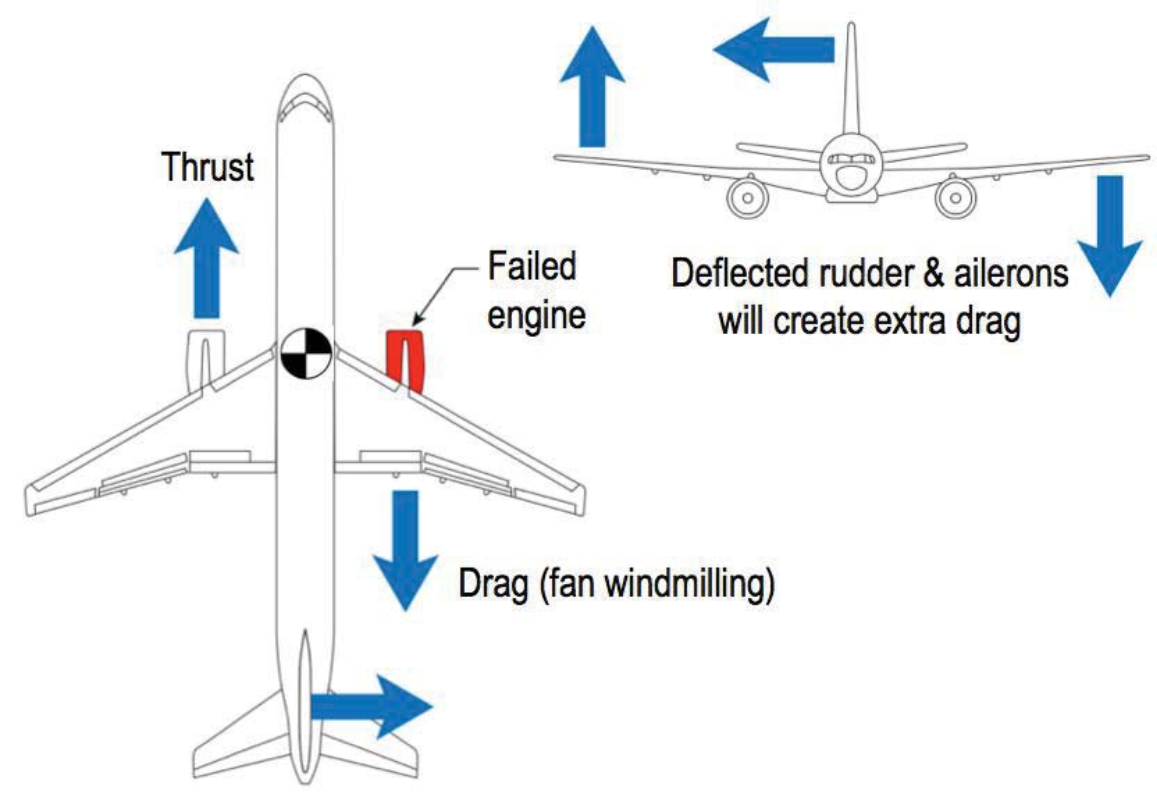

Figure 1. Aerodynamic forces that are generated on an airplane during an engine failure event.

Boeing Research and Technology (BR\&T) and NASA Langley Research Center (LaRC) agreed to jointly develop advanced AFC technology to achieve a substantial increase in the control authority of the vertical tail and rudder of a commercial airplane. Various AFC methods have been researched and have shown different degrees of effectiveness for different applications [3]. The capabilities of AFC have been demonstrated on airplane and component models in many laboratory and/or aerodynamic environments [4-10].

Rathay et al. $[4,5]$ applied synthetic jet actuators to a subscale $(\sim 7 \%)$ vertical tail model. Actuation placed upstream of the hinge of the rudder produced up to $20 \%$ side force increase at moderate rudder deflections. However, the benefits decreased at larger deflections. Seele, et al. $[6,7]$ applied sweeping jet actuators to a subscale $(\sim 14 \%)$ vertical tail model. Actuation was placed on the rudder [6] and on the main element's trailing edge [7]. Graff et al. [8] took that research a step further to incorporate different actuator size and spacing effects and discussed the effects of the sweeping jet actuators on the spanwise flow over swept wings. These studies [6-8] using sweeping jet actuators demonstrated significant side force enhancement of approximately $50 \%$ at large rudder deflections, zero sideslip, and reasonable mass flows. The sweeping jet actuator application on the trailing edge of the main element of the vertical tail was selected for the current full-scale wind tunnel test due to its simpler integration and design, as well as its control authority.

Sweeping jet actuators are attractive because they have no moving parts, but they do require a steady supply of compressed air. In this sense they resemble steady jets, but have been observed to require less mass flow to achieve similar aerodynamic effects to steady jets. A schematic drawing of a typical actuator from Raman and Raghu [9] is shown in Figure 2. It emits a continuous jet that flips from one side of the outlet nozzle to the other. The air passing 
through the "power nozzle" on the left of Figure 2 attaches itself to one of the solid surfaces forming the walls of the "interacting region" of the actuator (in the case shown it is attached to the upper surface). Due to the geometry of the "interacting region" the jet curves as it rushes to the actuator throat and increases the pressure at the inlet to the "feedback path" near the actuator throat. This creates flow in the "feedback path" that forces the jet to attach to the opposite surface of the "interacting region" and repeats the process. The frequency of the sweeping is a function of the actuator geometry and scale as well as the pressure (mass flow) driving the device. The interior features of the actuator do not have to be curved, as shown in Figure 2, to generate this behavior. Many previous experiments were carried out using rectangular actuators as described by Lucas et al. [10].

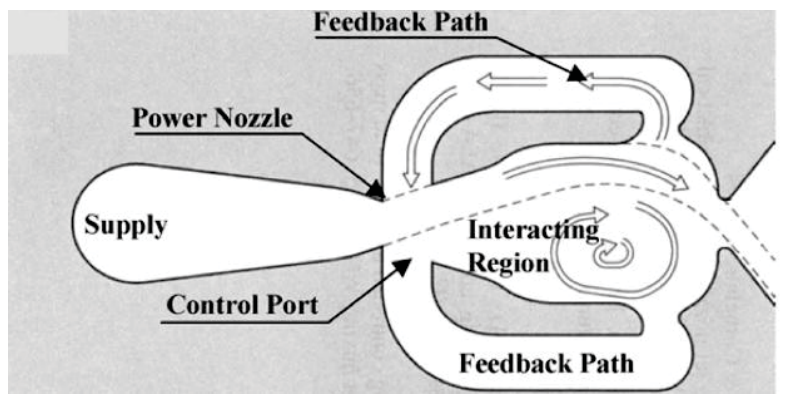

Figure 2. Conceptual design of sweeping jet actuator [9].

The objective of this full-scale wind tunnel test was to demonstrate that implementation of a sweeping jet AFC system on the vertical tail of a modern commercial transport could achieve a significant increase in side force at the maximum rudder deflection of $30^{\circ}$ at $0^{\circ}$ and $-8^{\circ}$ sideslip angles for takeoff flight conditions. Successfully demonstrating the AFC technology is a major risk reduction step toward a flight demonstration planned for 2015. The test also provided, for the first time on a commercial aircraft, the opportunity to assess design and scaling issues for full-scale application of AFC and validation of sub-scale and CFD observations regarding the sensitivities and effects of AFC on a vertical tail.

\section{Facility Description}

A full-scale AFC-enhanced vertical tail model was tested in the National Full-Scale Aerodynamics Complex (NFAC) 40- by 80-Foot (40x80) wind tunnel at NASA Ames Research Center. The NFAC 40x80 wind tunnel (Figure 3) has an 80-foot-long, closed test section and a closed-circuit air return passage. The speed range in the test section is continuously variable from 0 to 300 knots. The stagnation pressure in the tunnel is atmospheric, and stagnation temperature is uncontrolled, dependent on such things as outdoor temperature and the temperature rise due to tunnel operation. Aerodynamic force and moment data are measured using the wind tunnel's external floor balance system. In the current study, the full-scale vertical tail model was tested at a nominal speed of 100 knots $\left(\mathrm{M}_{\infty} \sim 0.15, \mathrm{Re} \sim 15\right.$ million $)$, a maximum speed of 130 knots $\left(\mathrm{M}_{\infty} \sim 0.2, \mathrm{Re} \sim 20\right.$ million $)$, and across rudder deflections $\left(0^{\circ}\right.$ to $\left.30^{\circ}\right)$ and sideslip angles $\left(+20^{\circ}\right.$ to $\left.-20^{\circ}\right)$ consistent with the vertical tail flight envelope. Notice that a negative sideslip angle is equivalent to a positive angle of attack in typical wing or airfoil coordinates.

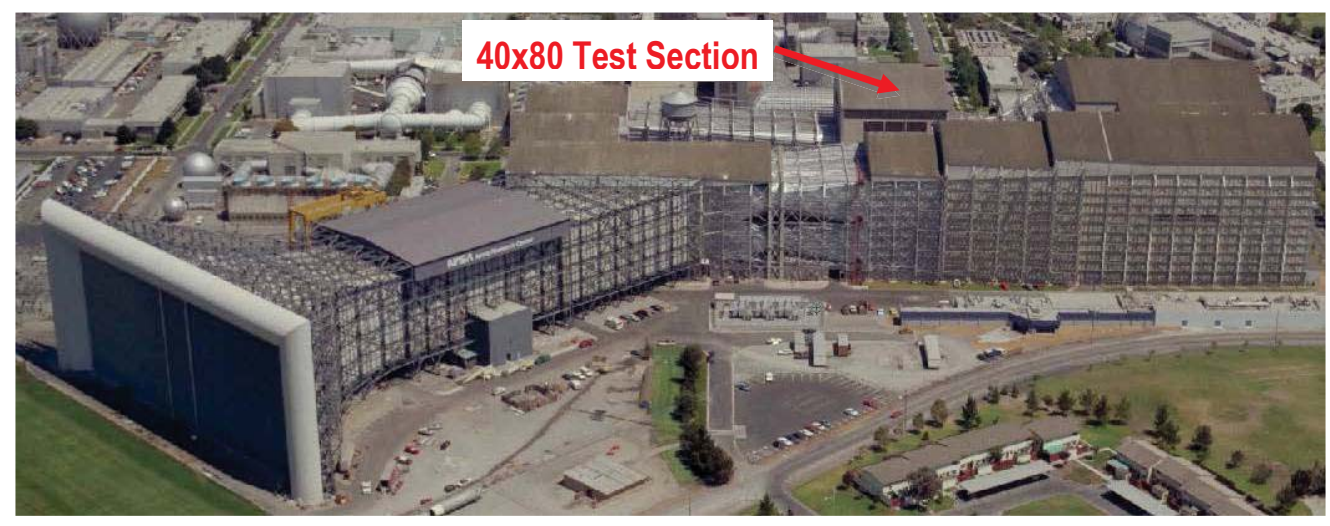

Figure 3. NFAC facility $40 \times 80$ foot wind tunnel. 


\section{Model Description}

\section{Boeing 757 Vertical Tail Model}

Boeing acquired a 757 vertical tail from an aircraft boneyard, Evergreen Air Center (Figure 4), near Tucson, AZ, and modified it to be used as a wind tunnel model at the NFAC 40 x80 wind tunnel. The 25 - $\mathrm{ft}$ tall, flighthardware tail was installed on top of a blister fairing inside the tunnel test section (Figure 4). The blister fairing is mounted to the tunnel turntable by an internal framework and is non-metric. It has several functions. First, it fairs over the metric model support structure that connects the model to the balance. Second, it raises the model out of the wind tunnel boundary layer. Third, it mimics the outer mold line of the 757 fuselage over the region where the rudder interfaces with the crown line of the fuselage. There are 316 static surface pressure taps installed on the model. Of those 316, 158 are located on the main element and 158 are located on the rudder. The pressure taps provided chord pressure distributions at 4 spanwise (vertical) stations as well as several spanwise stations. Surfacemounted tufts were used to visualize flow separation patterns on the rudder throughout the test period.
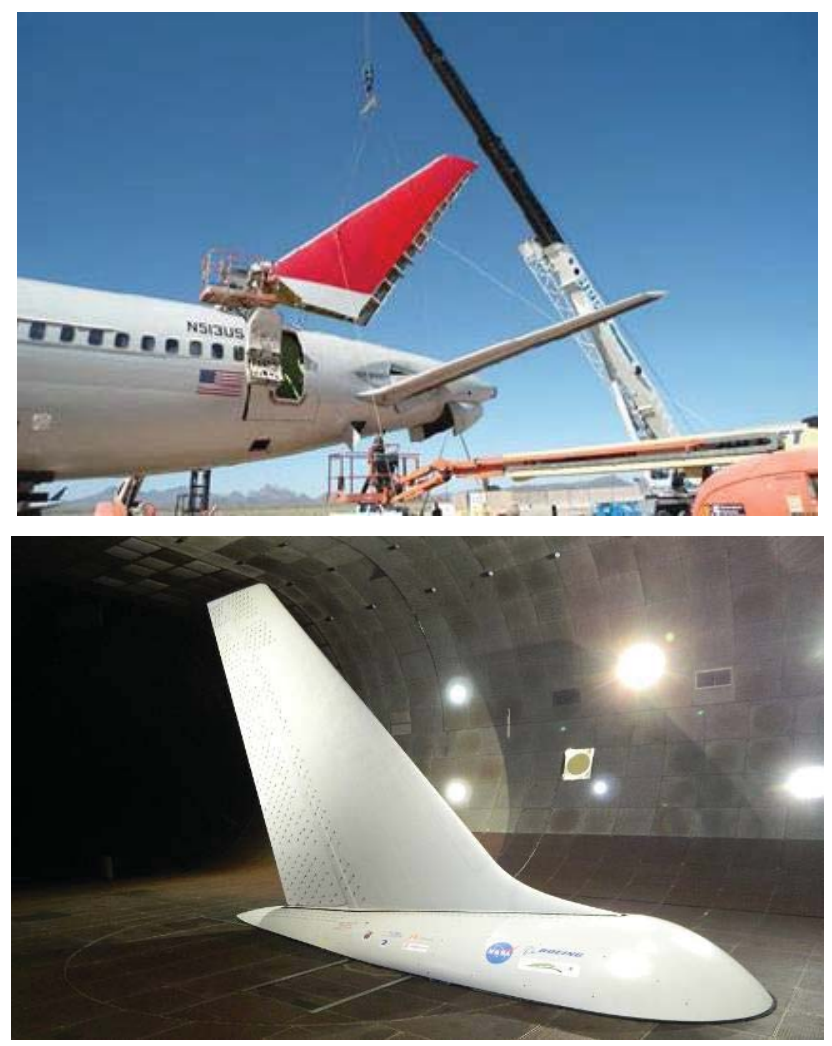

Figure 4. Boeing 757 vertical tail being removed at Evergreen Air Center (top) and the tail model installed on top of a blister fairing in the NFAC 40x80 wind tunnel (bottom).

\section{Sweeping Jet AFC System}

There are 37 sweeping jet actuators evenly spaced across the starboard span at the trailing edge of the main element and each actuator is independently controlled by a Wilkerson ER1-04 pressure regulator valve. The installation of the sweeping jet actuators is illustrated in Figure 5. The actuator panels are $\sim 3 / 8$ " thick and were set on top of the vertical tail skin. This was necessary because underlying structure could not be modified without compromising the integrity of the existing tail structure. Consequently, the actuator produced a small ( $\sim 3 / 8$ ') "bump" along the trailing edge of the main element (see Figure 5). This bump was faired-in with ramps at the upstream and downstream ends of the actuator blocks. In a new vertical tail design, the actuators would be designed into the vertical tail structure, avoiding this "bump". The trailing edge seal that was part of the original vertical tail design was replaced with bulb seal that provided a similar function. 

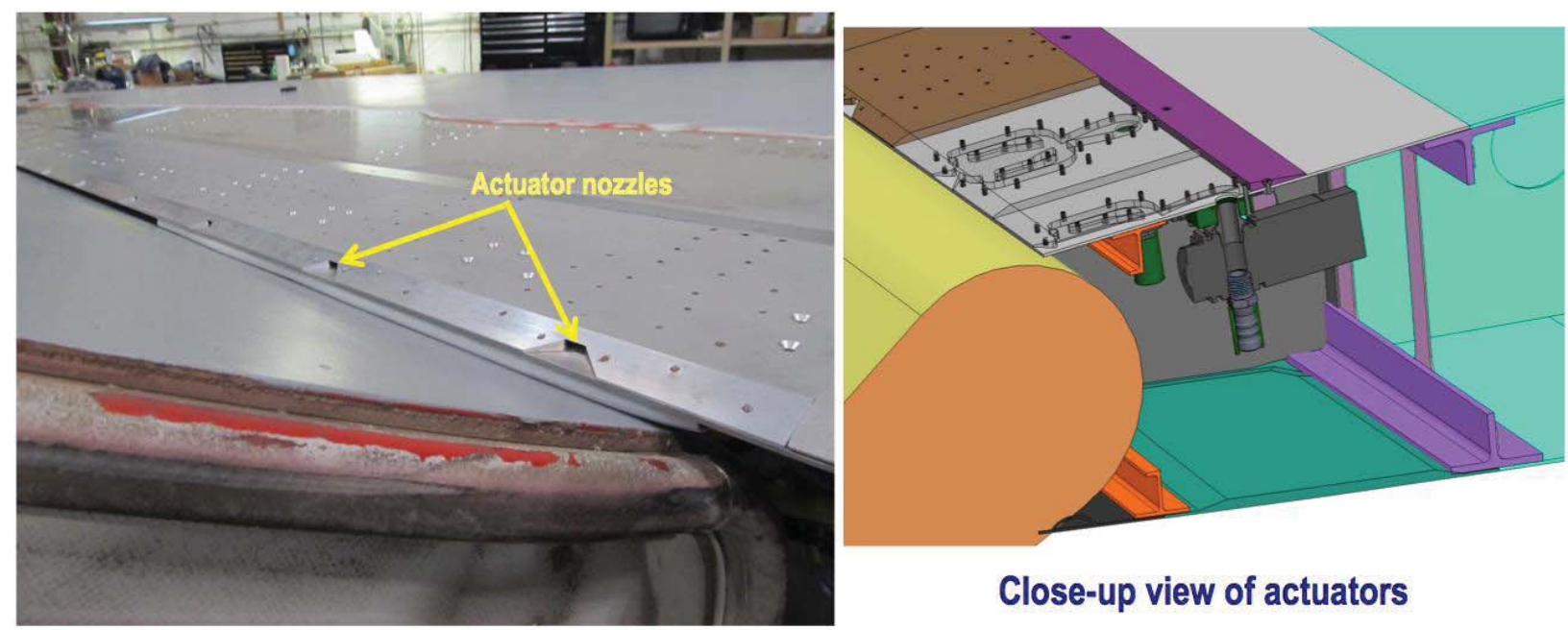

Figure 5. Sweeping jet actuator and Wilkerson valve installation on the model.

The NFAC High Pressure Air System (HPAS) provided the pressurized mass flow to the sweeping jet actuators. The HPAS can supply up to 40 pounds per second of air at up to $250^{\circ} \mathrm{F}$ through either one of two supply lines that run to the balance house below the wind tunnel floor. Flow rate or pressure in each line is independently controllable and temperature can be controlled as well. An Emerson Elite Coriolis Flow Meter (models F300S and F200S) was installed on each line to measure the mass flow rate. The two different flow meter models made it possible to make accurate mass flow measurements over the entire range of mass flow rates provided to the AFC system.

\section{Results and Discussion}

The wind tunnel investigation acquired aerodynamic data and corresponding AFC system data on the full-scale vertical tail model. Various actuation configurations were examined by using the Wilkerson valves to individually control the mass flow and the output pressure of each actuator. For example, the actuator spacing was varied by turning off individual actuators. Similarly, the effect of regions of actuation was explored by turning off actuators near the root and/or the tip regions. A number of actuator configurations produced a significant increase in side force at maximum rudder deflection $\left(30^{\circ}\right)$ and at the target sideslip angles $\left(0^{\circ}\right.$ and $\left.-7.5^{\circ}\right)$. Note that in the stability and control coordinate system used, positive rudder deflection and negative sideslip angle result in positive side force.

Figures 6(a) and 6(b) show the percentage change in side force coefficient $\left(\% \Delta \mathrm{C}_{\mathrm{y}}\right)$ relative to the baseline case (AFC off, tufts on) as a function of total mass flow rate $\left(\mathrm{m}_{\mathrm{dot}}\right)$ and actuator inlet pressure $\left(\mathrm{P}_{\text {Act_Inlet }}\right)$, respectively, at $\beta$ $=0^{\circ}$ and $-7.5^{\circ}$ for $\delta_{\text {Rudder }}=30^{\circ}$ and $\mathrm{U}_{\infty}=100$ knots. The $\Delta \mathrm{C}_{\mathrm{y}}$ of each case is normalized by the baseline (AFC off) $\mathrm{C}_{\mathrm{y}}$ at its respective $\beta$ to yield a $\% \Delta \mathrm{C}_{\mathrm{y}}$. A representative configuration using 31 sweeping jet actuators is shown in these figures. The theoretical inviscid performance of the vertical tail without AFC (calculated using CFD) is shown for $\beta=0^{\circ}$ for comparison purposes. It is provided as an indicator of system efficiency for flow separation control, as opposed to circulation control. As expected, the side force enhancement improved significantly with increasing mass flow rate and actuator inlet pressure. Nearly $30 \%$ side force increase was achieved at $\beta=0^{\circ}$. Because of the higher baseline value for $\mathrm{C}_{\mathrm{y}}$ at $\beta=-7.5^{\circ}$ and more adverse pressure gradient, more mass flow and pressure is required for the $\mathrm{AFC}$ to produce the same $\% \Delta \mathrm{C}_{\mathrm{y}}$ increase as observed for the $\beta=0^{\circ}$ case. This is illustrated by a similar parallel shift to the right in both mass flow and inlet pressure requirement for the same $\% \Delta \mathrm{C}_{\mathrm{y}}$ increment, which is an indication of a greater pneumatic power requirement for the $\beta=-7.5^{\circ}$ case. Typically, there is a $\% \Delta \mathrm{C}_{\mathrm{y}}$ decrease of $6 \%$ to $8 \%$ going from $\beta=0^{\circ}$ to $\beta=-7.5^{\circ}$ at the same $\mathrm{AFC}$ input level. 


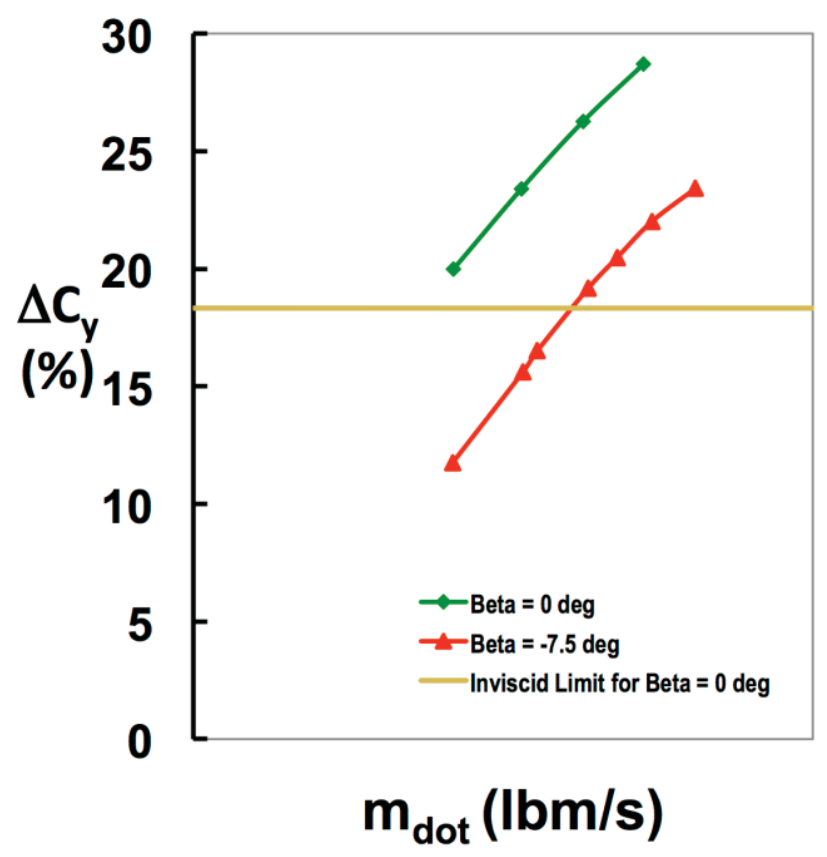

(a) Mass flow

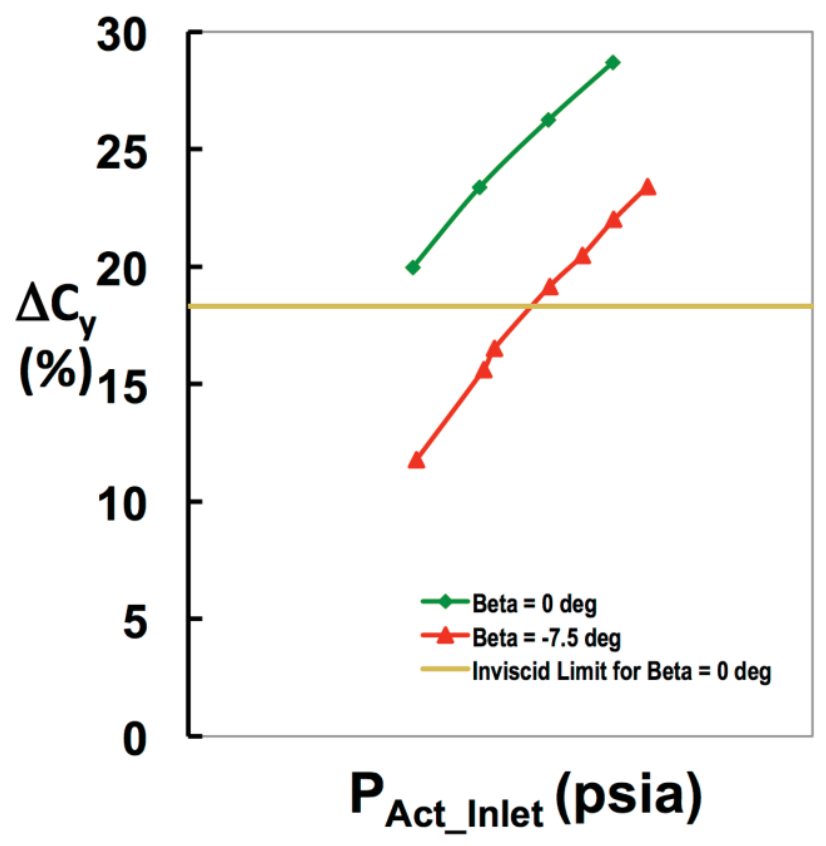

(b) Actuator inlet pressure

Figure 6. Side force enhancement versus mass flow and actuator inlet pressure for $\beta=0^{\circ}$ and $\beta=-7.5^{\circ}$ (31-actuators configuration, $\delta_{\text {Rudder }}=30^{\circ}, U_{\infty}=100$ knots).

Momentum coefficient $\left(\mathrm{C}_{\mu}\right)$ and power coefficient $\left(\mathrm{C}_{\pi}\right)$, as described in Seele, et al. [7], were two nondimensional parameters selected to quantify pneumatic requirements. They are defined as follows:

$$
\begin{aligned}
C_{\mu} & =\frac{\dot{m}^{2}}{\rho_{n} A_{n} q_{\infty} S} \\
C_{\pi} & =\frac{C_{Q} P_{\text {Act_Inlet }}}{q_{\infty}}
\end{aligned}
$$

Where $\dot{m}$ is the measured total mass flow rate, $\rho_{n}$ is the air density at the actuator nozzle, $A_{n}$ is the total area of actuator nozzle, $q_{\infty}$ is the tunnel dynamic pressure, $S$ is the model planform area, $C_{Q}$ is the mass flow coefficient $\left(\dot{m} /\left(\mathrm{U}_{\infty} \mathrm{S}\right)\right)$, and $P_{\text {Act Inlet }}$ is the averaged differential actuator inlet pressure.

Figures 7(a) and 7(b) show $\Delta \mathrm{C}_{\mathrm{y}}$ as a function of $\mathrm{C}_{\mu}$ and $\mathrm{C}_{\pi}$, respectively, at $\beta=0^{\circ}$ and $-7.5^{\circ}$ for $\delta_{\text {Rudder }}=30^{\circ}$ and $\mathrm{U}_{\infty}=100$ knots. Typically, a $\Delta \mathrm{C}_{\mu}$ of approximately $0.2 \%\left(\mathrm{C}_{\mu}\right.$ increase by a factor of 1.67$)$ is needed at $\beta=-7.5^{\circ}$ to achieve the same level of $\% \Delta \mathrm{C}_{\mathrm{y}}$ as the $\beta=0^{\circ}$ case, due to a higher baseline value for $\mathrm{C}_{\mathrm{y}}$ and more adverse pressure gradient for the former (Figure $7(\mathrm{a})$ ). Similarly, a $\Delta \mathrm{C}_{\pi}$ of approximately $5 \%\left(\mathrm{C}_{\pi}\right.$ increase by a factor of $\left.\sim 5\right)$ is needed at $\beta=-7.5^{\circ}$ to achieve the same level of $\% \Delta \mathrm{C}_{\mathrm{y}}$ as the $\beta=0^{\circ}$ case.

Although the bulk of the exploration of AFC effects was performed at a 30-degree rudder deflection, it is still important to determine the effectiveness of AFC at lower rudder deflections. Figure 8(a) and Figure 8(b) show the $\% \Delta \mathrm{C}_{\mathrm{y}}$ increase versus $\delta_{\text {rudder }}$ for $\beta=0^{\circ}$ and $\beta=-7.5^{\circ}$, respectively, for the representative 31 -actuator configuration at $\mathrm{U}_{\infty}=100$ knots. Both plots show that AFC remains effective for $\delta_{\text {rudder }}<30^{\circ}$ even though there is less flow separation on the rudder. However, the magnitude of $\% \Delta \mathrm{C}_{\mathrm{y}}$ increase at lower $\delta_{\text {rudder }}$ was less than at higher rudder deflections. 


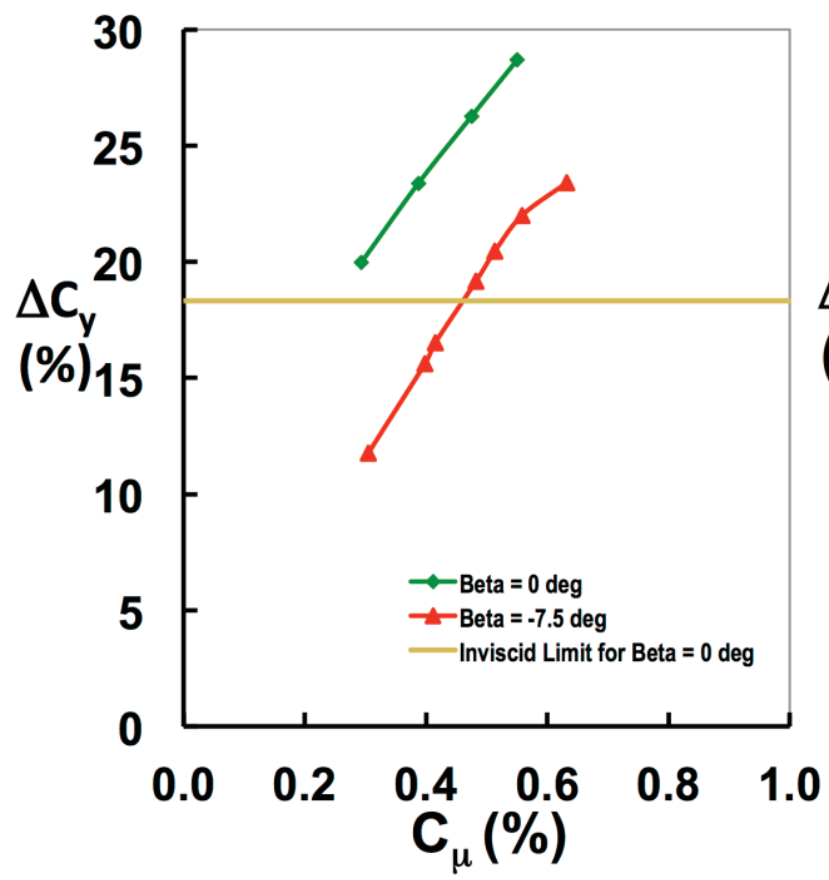

(a) Momentum coefficient

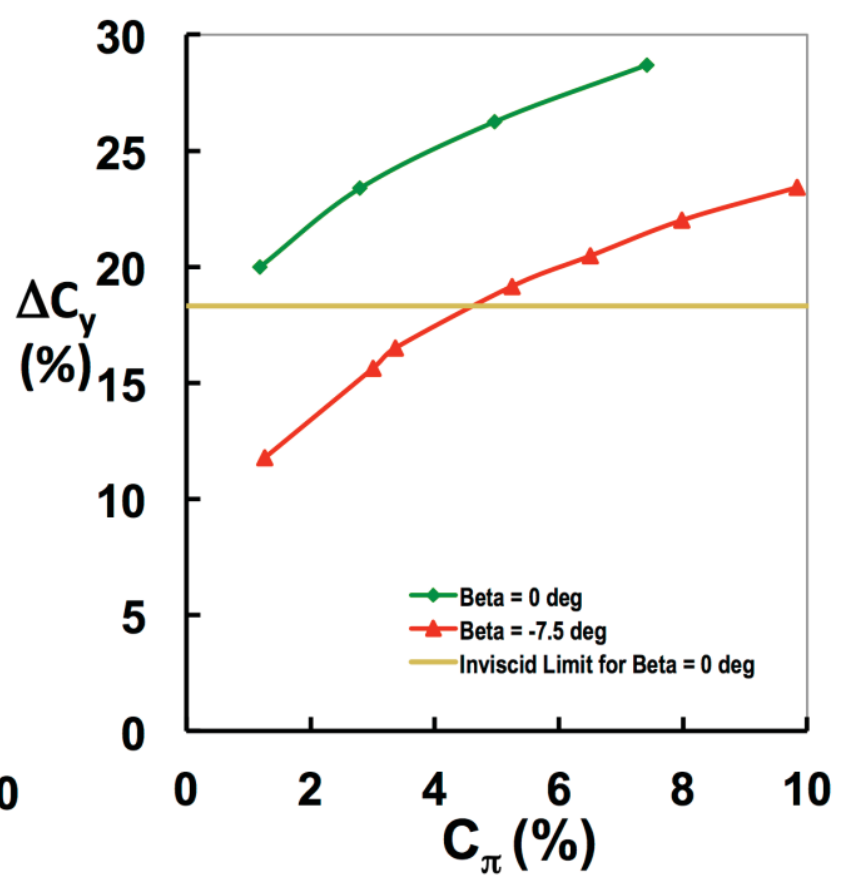

(b) Power Coefficient

Figure 7. Side force enhancement versus momentum and power coefficients for $\beta=0^{\circ}$ and $\beta=-7.5^{\circ}$ (31-actuators configuration, $\delta_{\text {Rudder }}=30^{\circ}, \mathbf{U}_{\infty}=100$ knots).

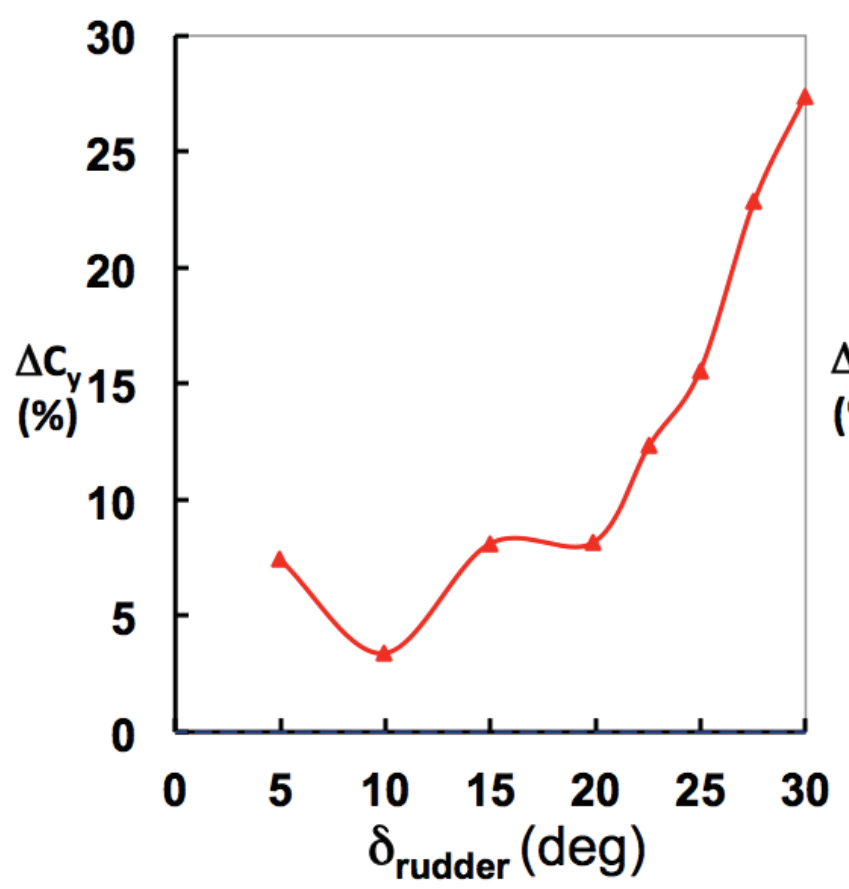

(a) $\beta=0^{\circ}$

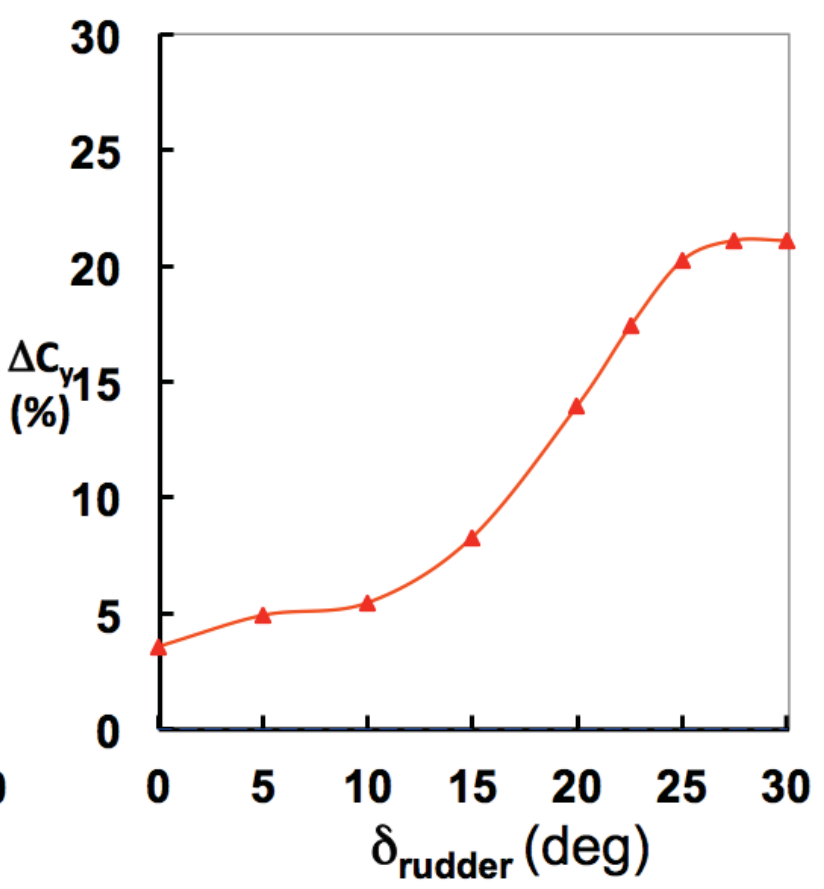

(b) $\beta=-7.5^{\circ}$

Figure 8. Side force enhancement versus rudder deflection for 31-actuator configuration ( $U_{\infty}=100$ knots). 
Figure 9(a) and Figure 9(b) show the chordwise $\Delta \mathrm{C}_{\mathrm{p}}$ distribution as a function of $\delta_{\text {rudder }}$ at $49.4 \%$ of the model span for $\beta=0^{\circ}$ and $\beta=-7.5^{\circ}$, respectively. The $\Delta \mathrm{C}_{\mathrm{p}}$ is the $\mathrm{C}_{\mathrm{p}}$ difference between $\mathrm{AFC}$ on and $\mathrm{AFC}$ off $\left(\mathrm{C}_{\mathrm{p} A F C}\right.$ on $\mathrm{C}_{\mathrm{p} \text { AFC off }}$ ) for the representative 31 -actuator configuration. Sweeping jet AFC increased the suction pressure across the actuator side, thereby producing the increase in side force observed in Figure 8 for all rudder deflections. A maximum suction $\Delta \mathrm{C}_{\mathrm{p}}$ of approximately -2.3 was achieved at the rudder hinge line for both sideslip angles. Perhaps because of increased boundary-layer separation for the non-zero sideslip angle, substantially higher suction pressure increments were observed for rudder deflection $\geq 20^{\circ}$ at $\beta=-7.5^{\circ}$. Increased pressure recovery is also observed for $\mathrm{x} / \mathrm{c} \geq 0.8$ at both sideslip angles. The pressure increase on the pressure (non-actuator) side is marginal for both cases.

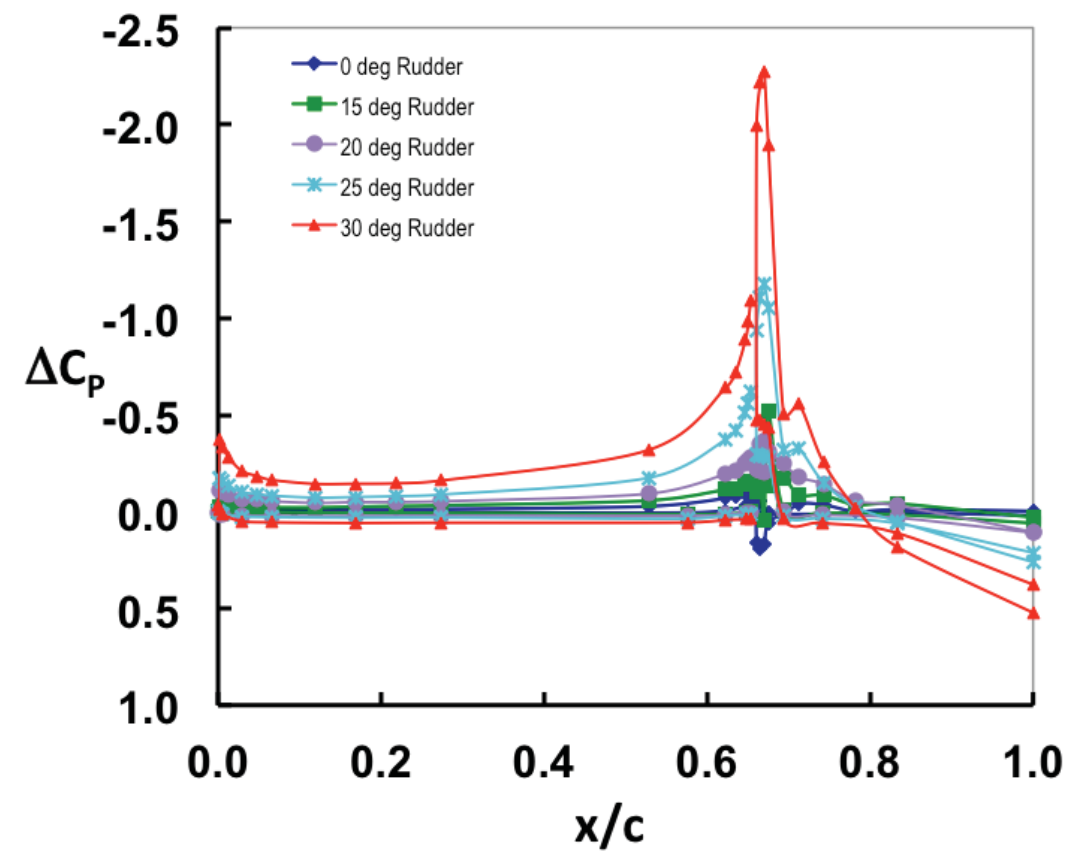

(a) $\beta=0^{\circ}$

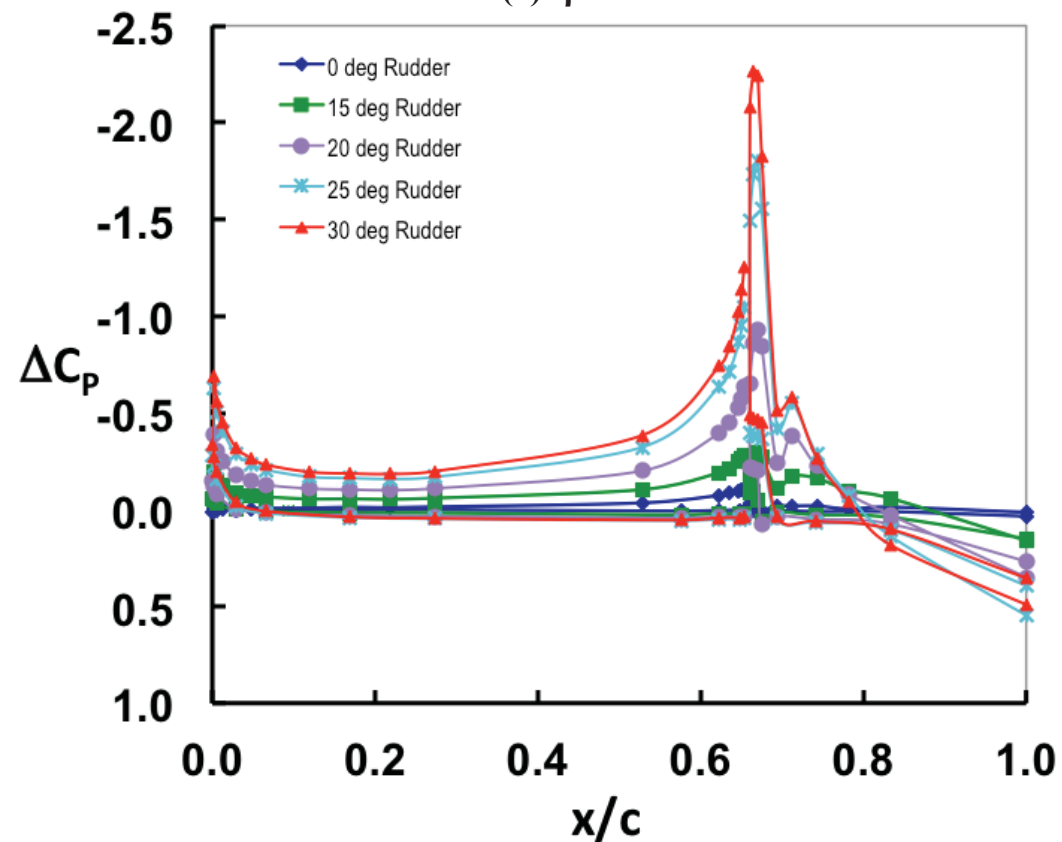

(b) $\beta=-7.5^{\circ}$

Figure 9. Delta chordwise pressure distributions for $\beta=0^{\circ}$ and $\beta=-7.5^{\circ}$ at $49.4 \%$ span (31-actuators configuration, $U_{\infty}=100$ knots). 
Similar to the $\% \Delta \mathrm{C}_{\mathrm{y}}$ versus $\delta_{\text {rudder }}$ plots shown in Figure 8, Figure 10(a) and Figure 10(b) show the effects of airspeed for $\beta=0^{\circ}$ and $-7.5^{\circ}$, respectively, for the 31 -actuator configuration at fixed pressure and mass flow input. The tunnel speed was varied from 60 to $130 \mathrm{knots}$ ( $\mathrm{Re} \sim 9$ to 20 million). As expected, the AFC was more effective at lower airspeeds because the ratio of actuator jet velocity to freestream velocity increased, which increased the momentum coefficient. The side force for the corresponding baseline cases with the AFC off did not exhibit any sensitivity to airspeed (Reynolds number). Past test data at high Reynolds number on a 3-element high-lift airfoil [11] indicated that there is little or no Re effect for $\mathrm{Re} \geq 9$ million. Because the AFC significantly increased the side force and because of the structural load limitations on the flight vertical tail, $\delta_{\text {rudder }}$ is limited to $25^{\circ}$ at $115 \mathrm{knots}$ and limited to $20^{\circ}$ at 130 knots for $\beta=0^{\circ}$ (Figure $10(\mathrm{a})$ ). At $\beta=-7.5^{\circ}, \delta_{\text {rudder }}$ is limited to $20^{\circ}$ at 115 knots and $15^{\circ}$ at 130 knots (Figure $10(\mathrm{~b})$ ). The $\% \Delta \mathrm{C}_{\mathrm{y}}$ improvement levels off at $\delta_{\text {rudder }}=25^{\circ}$ for $\beta=-7.5^{\circ}$. This is again an indication of the increased AFC required at non-zero sideslip angles.

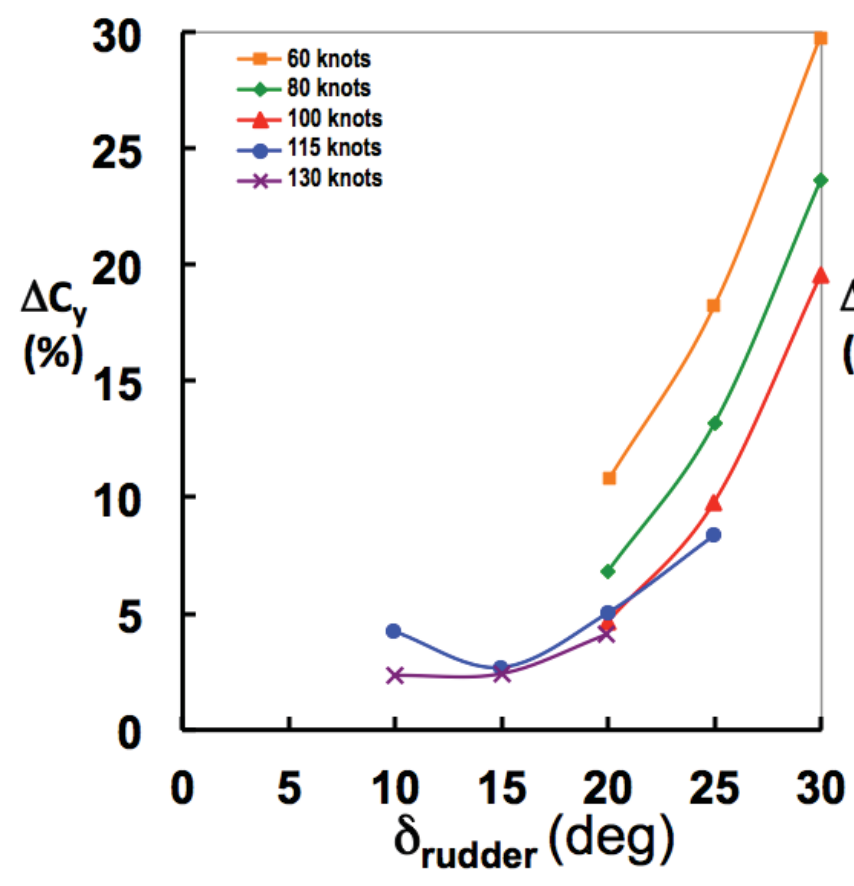

(a) $\boldsymbol{\beta}=\mathbf{0}^{\circ}$

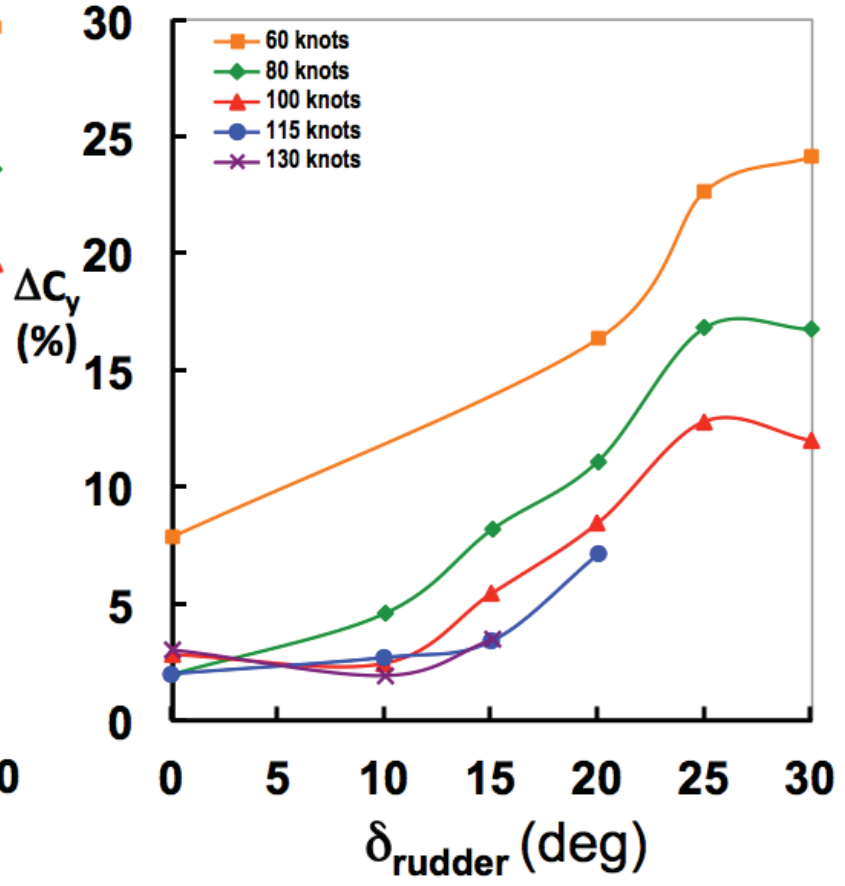

(b) $\beta=-7.5^{\circ}$

Figure 10. Side force enhancement versus rudder deflection for varying $U_{\infty}$ (31 actuators, $\beta=0^{\circ}$ and $\beta=-7.5^{\circ}$ ).

As part of the test campaign, the performance effects of vortex generators (VGs) were compared to those of the sweeping jet actuators. Vortex generators are typically used on vertical tails for reasons similar to those described for the sweeping jets. Figures 11 (a) and 11 (b) present $\% \Delta \mathrm{C}_{\mathrm{y}}$ versus rudder deflection at $\mathrm{U}_{\infty}=100 \mathrm{knots}$ for $\beta=0^{\circ}$ and $-7.5^{\circ}$, respectively. The VGs are moderately successful in providing side force enhancement (up to $\sim 10 \%$ ). However, their effectiveness levels off at $\delta_{\text {rudder }}=27.5^{\circ}$ and $25^{\circ}$ for $\beta=0^{\circ}$ and $-7.5^{\circ}$, respectively. Also presented in that figure are the effects of the surface tufts, which were removed prior to testing the VGs. The baseline cases with tufts fall within $\sim 2 \%$ of those without tufts $\left(\Delta \mathrm{C}_{\mathrm{y}}=0\right)$ for both sideslip angles. This suggests that the results observed for the sweeping jets can be compared directly to the VGs, despite the change to the model baseline configuration. Note that, as opposed to all previous plots, the cases in Figure 11 are normalized by the tuft-off baseline $\left(\Delta \mathrm{C}_{\mathrm{y}}=0\right)$ since the tufts were removed for each of the runs shown. Comparing the effects of the VGs to the 31 -actuator case shows that the sweeping jets provided at least twice the side force increase of the best VG configuration. The differences between them are even more dramatic at $\beta=-7.5^{\circ}$ and large rudder deflections, where the sweeping jets performed almost 4 times better at $\delta_{\text {rudder }}=25^{\circ}$ and nearly 10 times better at $\delta_{\text {rudder }}=30^{\circ}$ than the best VG configuration. 


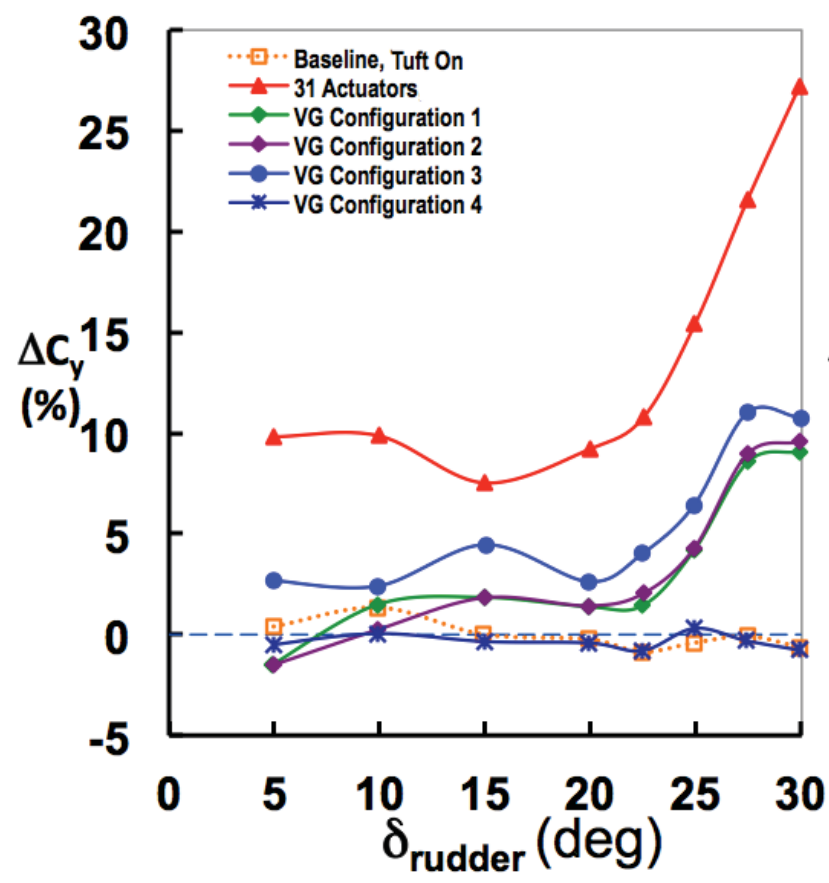

(a) $\beta=0^{\circ}$

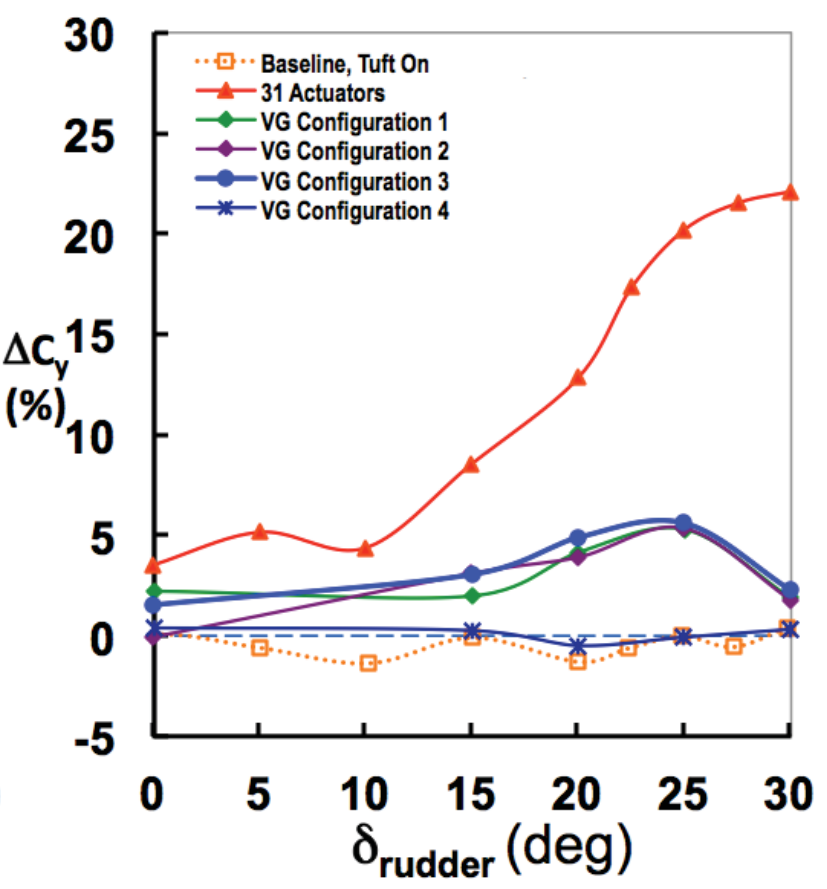

(b) $\beta=-7.5^{\circ}$

Figure 11. Side force enhancement versus rudder deflection for comparison with VGs $\left(\mathrm{U}_{\infty}=100\right.$ knots, tuft off, $\beta=0^{\circ}$ and $\left.\beta=-7.5^{\circ}\right)$.

\section{Concluding Remarks}

A full-scale Boeing 757 vertical tail model equipped with sweeping jet AFC technology was tested at the NFAC 40x80 wind tunnel. This test was part of a joint NASA/Boeing research project to develop AFC technology to enhance the aerodynamic performance of a vertical tail. It was a complex, multi-organizational and multidisciplinary effort. The NASA ERA project contributed, with the support of the California Institute of Technology (Caltech) and the University of Arizona, the sweeping jet AFC system and the wind tunnel test time. Boeing contributed the vertical tail model as well as the design and refurbishment of it for use as a wind tunnel model with AFC. The model was tested at a nominal airspeed of 100 knots and across rudder deflections and sideslip angles that covered the vertical tail flight envelope.

A successful demonstration of AFC-enhanced vertical tail technology was achieved. A 31-actuator AFC configuration produced a $20 \%$ or greater increase in side force at 100 knots for the maximum rudder deflection of $30^{\circ}$ at $0^{\circ}$ and $-7.5^{\circ}$ sideslip angles. Sweeping jet AFC required substantially higher pneumatic power at $\beta=-7.5^{\circ}$ to achieve the same level of percent side force increase as the zero sideslip case. The AFC-enhanced vertical tail technology is proceeding to a planned flight test on the Boeing 757 ecoDemonstrator in 2015.

\section{Acknowledgments}

This multi-organizational and multidisciplinary teaming effort involved many people who provided valuable contributions through their detailed work and/or expert guidance. The contributors have come from within the NASA/Boeing team and their partners. The NASA/Boeing collaboration was executed through a Space Act Agreement (Annex 8 to SAA1-1155). The NASA ERA project sponsored the sweeping jet AFC technology via Caltech (TEAMS 2 Contract NNL12AA09C) and the University of Arizona (direct subcontract). The ERA project also sponsored the wind tunnel test at NFAC (NIPR\# NNL12AA13T). The authors would like to thank key personnel in the following organizations for their excellent support during the course of this investigation:

Boeing Commercial Airplanes: Kate Nowicki (technology manager), John Brandt (stability \& control), Kyle Ford (loads \& dynamics), and Helen Mooney (aerodynamics). 
Boeing Research \& Technology: Bill Bower (flow control manager), David Bauer (model design), Tom VonHatten and Jonathan Lichtwardt (wind tunnel model and testing).

Boeing Engineering Operations \& Technology: Arvin Shmilovich (CFD).

Caltech: Elisa Phillips (actuator design), Roman Seele (subscale wind tunnel testing), and Mory Gharib (research manager).

NASA Langley Research Center: Mike Alexander (system engineering), Mehti Koklu (actuator geometry), Pamela Davis, Hamilton Fernandez, and Fay Collier (ERA managers).

NFAC 40x80 wind tunnel: Charlie Rogers (NFAC test director) and all NFAC staff.

NASA Ames Research Center: Robert Fong (NASA Ames test engineer/coordinator).

\section{References}

[1] Collier, F. S., Thomas, R, Nickol, C. A., Lee, Chi-Ming, Tong, M., "Environmentally Responsible Aviation Real Solutions for Environmental Challenges Facing Aviation, 27th International Congress of the Aeronautical Sciences, Paper No. 802, Nice, France, September 19-24, 2010.

[2] Bezos-O'Conner, G.M., Mangelsdorf, M.F., Maliska, H.A., Washburn, A.E., Wahls, R.A., "Fuel Efficiencies Through Airframe Improvements", AIAA 2011-3530, 29th AIAA Applied Aerodynamics Conference, Honolulu, HI, June 27-30, 2011.

[3] Cattafesta III, L.N. and Sheplak, M., "Actuators for Active Flow Control", Annual Review of Fluid Mechanics, Vol. 43, Issue 1, August 2010, pp. 247-272.

[4] Rathay, N., Boucher, M., Amitay, M. and Whalen, E., "Performance Enhancement of a Vertical Stabilizer using Synthetic Jet Actuators: No Sideslip", AIAA 2012-0071, 50th AIAA Aerospace Sciences Meeting, Nashville, TN, January 9-12, 2012.

[5] Rathay, N., Boucher, M., Amitay, M. and Whalen, E., "Performance Enhancement of a Vertical Stabilizer using Synthetic Jet Actuators: Non-zero Sideslip", AIAA 2012-2657, 6th AIAA Flow Control Conference, New Orleans, LA, June 25-28, 2012.

[6] Seele, R., Graff, E., Gharib, M., Taubert, L., Lin, J. and Wygnanski, I., "Improving Rudder Effectiveness with Sweeping Jet Actuators", AIAA 2012-3244, 6th AIAA Flow Control Conference, New Orleans, LA, June 25$28,2012$.

[7] Seele, R., Graff, E., Lin, J. and Wygnanski, I., " Performance Enhancement of a Vertical Tail Model with Sweeping Jet Actuators", AIAA 2013-0411, 51st AIAA Aerospace Sciences Meeting, Grapevine, Texas, January 7-10, 2013.

[8] Graff, E., Seele, R., Lin, J., and Wygnanski, I., "Sweeping Jet Actuators - A New Design Tool for High Lift Generation," NATO Workshop on Innovative Control Effectors for Military Vehicles (AVT-215), Stockholm, Sweden, May 2013.

[9] Raman, G. and Raghu, S., "Cavity Resonance Suppression Using Miniature Fluidic Oscillators", AIAA Journal, Vol. 42, No. 12, December 2004, pp. 2608-2611.

[10] Lucas, N., Taubert, L., Woszidlo, R., Wygnanski, I., and McVeigh, M. A., "Discrete Sweeping Jets as Tools for Separation Control," AIAA 2008-3868, 4th AIAA Flow Control Conference, Seattle, WA, June 23-26, 2008.

[11] Valarezo, V.O., "High Lift Testing at High Reynolds Numbers", AIAA 92-3986, AIAA 17th Aerospace Ground Testing Conference, Nashville, TN, July 6-8, 1992. 